
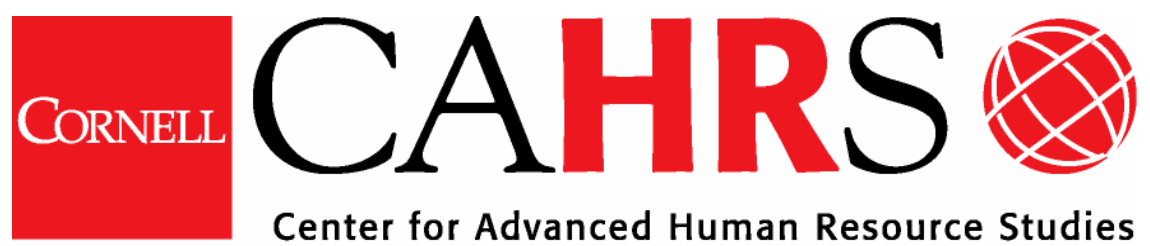

Center for Advanced Human Resource Studies

CAHRS / Cornell University 187 Ives Hall

Ithaca, NY 14853-3901 USA

Tel. 607 255-9358

www.ilr.cornell.edu/CAHRS/

Ulohing Paper Sebleg

\title{
Partner or Guardian? HR's Challenge in Balancing Value and Values
}

Patrick M. Wright

Scott A. Snell

Working Paper 04 - 11

CORNELL ilr School of Industrial and Labor Relations 


\title{
Partner or Guardian? HR's Challenge in Balancing Value and Values
}

\author{
Patrick M. Wright \\ Scott A. Snell \\ School of Industrial and Labor Relations \\ Cornell University \\ Ithaca, NY 14853-3901
}

July 2004

http://www.ilr.cornell.edu/cahrs

This paper has not undergone formal review or approval of the faculty of the ILR School. It is intended to make results of Center research available to others interested in preliminary form to encourage discussion and suggestions.

Most (if not all) of the CAHRS Working Papers are available for reading at the Catherwood Library. For information on what's available link to the Cornell Library Catalog:

http://catalog.library.cornell.edu if you wish. 
Abstract

To appear in: S. Meisinger, M. Losey, and D. Ulrich (Eds) The Future of HR: 50 Thought Leaders Call for Change. NY: John Wiley and Sons 


\section{Partner or Guardian? HR's Challenge in Balancing Value and Values}

Two roads diverged in a wood, and I-I took the one less traveled by. And that has made all the difference. -Robert Frost

Is HR at a crossroad? A number of signs seem to be pointing that way. Increasingly HR executives are faced with a critical decision: Will they continue on their journey to be business leaders, , with full sway and equal influence in organizational decision making, or will they take the short-cut by sacrificing professional ethics and values for a "seat at the table." This challenge is exemplified by the story of Delta Airlines.

Since its founding, Delta Airlines was always distinct in its ability to deliver outstanding service to its customers, and its family atmosphere which attracted and retained the most talented people in the industry. However, in the early 1980's, deregulation enabled low cost entrants to establish a foothold in Delta's major markets. In the early 1990's the globalization of the industry prodded Delta to expand by purchasing Pan Am's European routes. Finally, the changing information technologies were resulting in price competition within the industry. Faced with these challenges, Delta embarked on a strategic change called Leadership 7.5. (Brannigan \& Lisser, 1996)

Leadership 7.5 was a massive effort to reduce Delta's costs from 10 cents per available seat mile, to match Southwest's 7.5 cents. It entailed massive workforce transformation, with highly skilled, committed, and experienced workers being shed and replaced by a lower paid contingent workforce lacking in skills, commitment, and experience. The effort resulted in Delta's return to profitability, however, with an organization that was only a shadow of its former self. (Brannigan \& White, 1997)

Where has this led? Today Delta's revenue growth lags that of the rest of the industry. Their core business customer fled for Continental years ago. The unions have been knocking on Delta's doors, and employees have been ready to answer it. And, talent is fleeing, with six of its top ten executives leaving in the past year. 
What happened at Delta? Most of us would recognize-perhaps in retrospect-the detrimental effects of these HR decisions at Delta. But would we have a deep understanding of the firm's economic model to articulate the negative outcomes in a way that is compelling to the executive leadership. Perhaps more importantly, would we have the courage to be the voice of dissent that has sway in the strategic decision. In many ways, this story serves as a real life allegory that illustrates the past mistakes of one organization while also laying out the three future challenges faced by the field of HR.

The first challenge refers to value creation and describes the almost "Perfect Storm" of influences that have called into question the viability of every firm's preexisting business model. Creating value in a global economy requires that HR executives clearly understand the confluence of economic, social, and technological forces that drive industry competition. Do we? The second challenge, Value Delivery, deals with the pressing need for HR functions to demonstrate its tangible impact by aligning with and driving the issues critical to the business. Finally, Living Values recalls us as a profession to rediscover that we are not just order takers or implementers, but are the guardians of our organizations. We guard and preserve its strategic capability, we guard its people, and we guard its values. When we fail to guard these things, our firms fail. They fail financially, strategically, legally, and morally.

In this chapter we will examine these challenges, and provide a model for understanding how the competing demands placed on HR create both organizational and professional conflict. In order to do so, we first address the current trends in firms' competitive environments and how these trends are revolutionizing the demands placed on HR professionals and organizations. We then discuss the need for HR functions to balance their needs to execute for the business while investing in their own functional capability. Finally, we propose the "SELF" (strategic, ethical, legal, and financial) model as a framework for identifying some of the main demands placed on HR as well as how these demands often conflict with one another, resulting in tremendous challenges for HR professionals. Finally, we discuss the implications of these competing demands for the future of the profession. 


\section{The Value Creation Challenge}

Over the past decade, numerous researchers have attempted to reveal the "future" trends impacting organizations. In 1995 Ulrich and Eichinger identified globalization, and technological change as some of the major environmental developments that would influence organizations during the late 90's. Caimano, Canavan, \& Hill (1998) identified the same basic issues in their canvassing of the trends that would impact organizations and HR. Based on interviews and surveys of over 150 HR thought leaders world-wide, Wright, Takla, \& Dyer (1999) identified globalization, increased competition, and technological change, as the three major trends that would impact organizations.

Interestingly, regardless of methodology, researchers, or scope, certain trends stand out. First, globalization seems to top the list of concerns for just about every organization today. In some cases the concern arises as firms increase to seek to maximize their global presence. The increase in global presence stems in part from the desire to better distribute and sell their products, but increasingly also derives from aspiring to capitalize on labor cost advantages. In other cases, firms in domestic markets increasingly face competition from global competitors.

Second, no one argues with the fact that technological change has driven, and continues to drive competition. Again, in some cases firms such as Intel or Microsoft seek to drive the changing technologies, forcing others to play catch up. In other cases firms such as Amazon or Wal-Mart seek to leverage the new technologies being developed in order to change the nature of the competitive environment.

While other trends may be unique to particular industries or product markets, these trends universally influence the competitive landscape: Globalization, increased competition, and technological change. The synergistic result of these forces, is to commoditize the marketplace for products and services. Consider: Toys R' Us faces Wal-Mart; IBM faces Dell, Delta Airlines faces Southwest, Jet Blue, and ATA. Over the past few years, the low price competitors have tended to dominate every industry, making price a, if not the most significant criterion in the buying choice. 
The commoditization process drives firms to reduce their cost base, having a number of implications for HR. First, because labor costs usually comprise a firm's largest single controllable cost, this becomes the focus of a number of strategies and tactics. Firms seek to limit the increase in hourly wages through small wage increases, and requiring them to increase their contributions to health care premiums. Firms also seek to move more and more work off shore to capitalize on the lower labor costs. Finally, the labor cost pressure leads firms to increasingly manage costs by more quickly downsizing in response to decreased product demands. Second, this has heightened the role and accountability of the HR function for actually delivering value.

Here's the challenge: Without a real understanding of the firm's business drivers, HR executives can become complicit in the "cost cutting" game. This has three detrimental effects of the sustainability of a firm's business model. First, it cuts the core talent that leads to value creation. Second, it trades short-term costs for long-term (total costs). This is the lesson that firms are learning about offshoring employment models. Third it diminishes the potential for real innovation. While forces toward commodization are driving the economics of business, the requirements for innovation and product development are changing the pace and structure of industries

\section{The Value Delivery Challenge}

With a heightened sensitivity to the very real tangible costs of supporting an HR function compared to the less tangible benefits accrued, HR organizations will continue to face the challenge of delivering value.

This value must be demonstrated both quantitatively and qualitatively. The recent focus on developing a set of comprehensive HR metrics exemplifies the importance that HR functions place on providing quantitative data to demonstrate the value of HR. However, no matter how extensive these metrics become and no matter how useful they are for internal HR assessment and decision-making, they still seem to fall short of fully convincing those outside HR of its value. Rather, as firms seek to attract, motivate, and retain talent and to build organizational 
capability for leadership, the qualitative value that HR delivers seems to become more readily apparent.

In addition, the perceived value emanating from HR clearly increases with HR's improvement in the execution of HR activities. Such execution currently focuses on two aspects: Doing the right things, and doing things right. Doing the right things requires focusing time and energy on the most important value creating or value impacting dimensions of HR. Doing things right entails providing near perfect execution in all those activities.

Finally, meeting the value delivery challenge requires managing the HR function as a business, with as much attention paid to building the core competence of the function as to the actual delivery of products and services to customers. But they have to be careful not to outsource the competence in order to cut costs. Particularly over the past few years, as the economy has suffered, HR functions have obsessed about doing whatever is asked by the line, whenever it is asked, while virtually ignoring the activities that build HR capability. One often hears about HR being so focused on fighting fires that they cannot engage in strategizing, but this is worse. In essence, our functions have become like marathon runners that keep running and running, but never stop to eat. It can only last for so long, and then sooner or later, the runner, or the function, collapses.

\section{The Living Values Challenge}

The final, and we believe most pressing challenge is for HR to rise up to truly live, model, and promote the values that have historically characterized our profession, but that are also necessary for long term organizational success. To do so will continue to increase in difficulty as organizations become more and more cost focused and demand more and more accountability from HR.

The problem is actually described by what we heard at a meeting of some SVPs of HR. Before the session began, these executives, who all knew one another, began what one might describe as a therapy session, or better yet, a catharsis. We heard one executive bemoaning his organizations downsizing effort because in spite of all the data they had showing that the 
best predictor of same store sales was the average tenure of the sales associates, those were the people being targeted by top managers' layoffs. We heard an executive complaining about how top managers were requiring an extra $\$ 500$ contribution for hourly employee health care coverage, while they weren't even willing to entertain the notion that they should pay anything for their top-hat coverage. We heard an executive whose company met none of its goals, and whose average bonus payout was $10 \%$ of target, complain of the compensation committee's obstinate insistence that the CEO receive $100 \%$ of his target bonus, because "It's a retention issue." What did the executive do? What would you do?

As we have listened to these, and a number of other stories, we have found that they often describe the conflict that occurs when competing values conflict with one another. What are these values? We would suggest that, while not exhaustive, the most predominant are the following: strategic, ethical, legal, and financial.

Strategic value is concerned with building an organization which is capable of delivering customer outcomes. The priorities of this value system consist of processes, technologies, culture, and the skills and commitment of the workforce. Ethical values relate to doing what is morally right. Such values place priority on social responsibility, organizational values, and individual integrity. Legal values focus on not violating the law. Priority is given to compliance with existing legal and regulatory systems, and the avoidance of lawsuits and legal proceedings. Finally, financial values aim at increasing shareholder wealth. Such values give priority to cost control, margin management, and return on investment.

All of these values share legitimacy, but problems often arise because they really or seemingly become mutually exclusive with regard to particular decisions. For instance, consider the recent travails of Boeing. According to recent BusinessWeek, articles (Holmes, 2004; Holmes \& France, 2004), years ago internal HR professionals at Boeing discovered some pay disparities between the male and female engineers. Now, consider what your options might be as an HR executive. First, you could come forward and admit the disparities, and consequently raise the female pay to achieve equity. However, do to so would come at 
considerable financial cost, and would open the firm up to legal liability for past inequities (with additional financial costs). Second, you could try to keep it secret while you attempted to raise the pay to equitable levels over time. This might reduce the financial cost, but leave you open to legal liability (if discovered), and would raise ethical questions (is it right to knowingly let female workers be underpaid for the time frame during which you will work to achieve equity?) The point is not to single out Boeing (indeed, many companies face similar challenges) nor to suggest any wrongdoing on Boeing's part, but rather to illustrate how the competing values create tensions and challenges for HR professionals.

In contrast, consider Eaton Corporation, a highly values driven company. A former student related a story of how when selling a plant, Eaton used part of the sale price to fully fund the pensions of the employees of the plant, even though it was at financial cost to the company, and there was no legal obligation to do so. When we questioned Eaton's SVPHR, Sue Cook, about it, she looked somewhat confused. Not because she didn't remember it, but because she didn't know to which of the many instances we referred. "We do that quite frequently. We do it because it's the right thing to do" she said. When asked what their shareholders thought of it, the answer was "That's why they buy Eaton stock. They know the way we run the company will pay off in the long term."

\section{Conclusion}

The HR profession has reached a critical juncture in its history. We are being asked to be business partners, and business driven, yet we frequently face situations where our historic values conflict with short term decisions made in the business. Bill George, retired CEO of Medtronic argues that deviating from values can be costly. To illustrate, he relates this story:

Recently I used the Enron-Arthur Andersen debacle to make this point with a class of MBA students. I described Arthur Andersen as a tragedy, saying "you can spend fifty years in establishing your reputation, and lose it in a day." A Dutch student challenged my characterization, “No Bill, Andersen didn't lose it all in a day. They sold their soul to their clients over the last five to ten years by compromising their values more and more, just to make money. What looks to 
you like a giant step in destroying documents was to them just another step in sacrificing values for greed." He was right. What appears to be a compromise of values in a single instance is usually the final act in a series of compromises. (George, 2003, p. 75.)

This story as well as the stories of Delta and Boeing challenges the HR profession. We seek to be business partners, but if we take the short-cut by sacrificing our values and integrity for a seat "at the table", we may actually end up playing a significant role in the demise of our organizations. Instead, HR leaders require the vision and courage to integrate the different value systems in an organization for its long-term viability.

This is not blue-sky idealism. Although competitive realities require that HR organizations are business-oriented, HR leaders need to distinguish between decisions that are driven by the business and decisions driven for the business. A focus on short term financial returns for fickle investors may be made at the long term cost of organizational viability. As the Delta story shows, HR leaders need to be the guardians of our firm's strategic capability. As the Boeing story shows, HR leaders need to be the guardians of its ethical and moral integrity. As we increasingly are asked to play a significant role in these types of decisions, let us hope that no one ever need ask, "Quis custodiet ipsos custodies" ("Who must guard the guardians?" from Satires of Juvenal). 


\section{References}

Brannigan, M. \& Lisser, E. (1996). "Ground Control: Cost Cutting at Delta Raises Stock Price but Lowers the Service." Wall Street Journal, June 20, 1996.

Brannigan, M. \& White, J. (1997) "'So Be It:" Why Delta AirLines Decided it Was Time For CEO to Take Off" Wall Street Journal, May 30, 1997. A1.

Caimano, V., Canavan, P., \& Hill, L. (1998). 1998 State-of-the-Art \& Practice (SOTA/P) Report. New York: HRPS

George, B. (2003). Authentic Leadership: Redescovering the Secrets to Creating Lasting Value, San Francisco, CA: Jossey Bass.

Holmes, S. (2004). A New Black Eye For Boeing?; Internal documents suggest years of serious compensation gaps for women. Business Week. New York: Apr 26, 2004. p. 90

Holmes, S, \& France, M. (2004). Coverup at Boeing? Business Week, June 28, 2004, 84-90.

Ulrich, D. \& Eichinger, R. (1995) 1995 State-of-the-Art \& Practice (SOTA/P) Report. New York: HRPS

Wright, P., Dyer, L., \& Takla, M. (1998). 1998 State-of-the-Art \& Practice (SOTA/P) Report. New York: HRPS 